\title{
Cineclubes piratas: aparatos tradicionais com tecnologia imprópria
}

\section{Pirate film societies: traditional apparatus with inappropriate technology}

\section{Gabriel Menotti Gonring}

Professor Adjunto do Departamento de Comunicação da UFES, com um doutorado em Media and Communications por Goldsmiths (Universidade de Londres) e outro em Comunicação e Semiótica pela PUC-SP.

<gabriel.menotti@gmail.com>

\section{RESUMO}

Acompanhando os primeiros anos de funcionamento de um cineclube pirata, esse artigo busca demonstrar como os dispositivos cinematográficos podem ser rearranjados utilizando novas tecnologias. Ao fazê-lo, examina a lógica por trás do processo de especificação da tecnologia mediática, prestando atenção tanto no engajamento direto com a distribuição e consumo de filmes quanto no estabelecimento de estruturas ancilares para a promoção e regulação destas atividades.

\begin{abstract}
Following the first years of a pirate film society, this paper means to show how cinematographic apparatus can be rearranged using new technologies. By doing so, it examines the logic behind the specification of media technology, taking into account both the direct engagement in film distribution and consumption and the establishment of ancillary structures to promote and regulate such activities
\end{abstract}

Keywords: Film distribution. P2P. Medium specificity.

Era uma exibição de filmes que eu estava organizando com alguns amigos, mas não consigo precisar a data. Talvez fosse capaz de checar essa informação em algum dos muitos pôsteres xerocados que usamos para divulgar o evento, mas é difícil encontrar esse material hoje em dia. A maior parte foi destruída quando se tornou evidência do crime. Até mesmo os banners de Internet foram apagados. Tudo o que tenho certeza é que era 2004, e provavelmente uma quarta-feira, pois esse era o dia em que as sessões do Cine Falcatrua costumavam ocorrer.

A falta de referências é esperada. Quando não havia praticamente nenhum cinema digital no país, o Cine Falcatrua organizava sessões abertas e gratuitas usando computadores domésticos: os PCs serviam como aparelho de reprodução de filmes e as redes de troca de arquivo ponto-a-ponto como recurso curatorial. Por causa das associações dessa prática com a pirataria, o cineclube precisava ser muito consciente com os rastros que deixava. 
Nesse artigo, buscarei dar conta desse objeto tão elusivo ao revisitar memórias pessoais. Pretendo avaliar qual papel as exibições desautorizadas do Cine Falcatrua, entre outras atividades "piratas", podem ter no desenvolvimento de práticas midiáticas. Essa análise se valerá das ideias do filósofo Gilbert Simondon, e em particular do seu entendimento das entidades técnicas como "unidades de devir" (1958, p. 19).

No caso, devir se refere ao processo evolutivo pelo qual uma entidade passa de modo a se tornar "um sistema inteiramente coerente consigo mesmo e inteiramente unificado" (Simondon, 1958, p. 21). Sob essa luz, os dispositivos que constituem o circuito cinematográfico aparecem não como totalidades fixas, mas sim como arranjos de diversos elementos sócio-técnicos, cristalizados temporariamente. Uma prática como a exibição de filmes, por exemplo, deveria ser vista como um aglomerado que se concretiza conforme seus elementos convergem para a unidade (Simondon, 1958, p. 15).

Ao retraçar as atividades do Cine Falcatrua, pretendo indicar de que modo elas podem ter contribuído para esse processo de concretização do cinema, ao produzir novas sinergias entre aparelhos preexistentes. A partir daí, seria possível imaginar outras transformações que as práticas piratas implicam nos modos de engajamento do público com o seu entorno técnico.

\section{Práticas cotidianas e circunstâncias sócio-técnicas emergentes}

O Cine Falcatrua começou como um cineclube da Universidade Federal do Espírito Santo. Ainda que estivesse registrado como um projeto de extensão do Departamento de Comunicação Social, funcionava de maneira praticamente autônoma. O apoio do Departamento era principalmente pro forma: um aval que possibilitava usar os equipamentos da universidade, como projetores de vídeo e auditórios. Já o planejamento e organização das sessões ficava por conta dos próprios estudantes - um grupo formado por cerca de dez egressos dos cursos de Jornalismo, Artes e Psicologia.

É impossível ser preciso a esse respeito porque o número de participantes flutuava muito. Como numa típica atividade grassroots, a divisão de papéis entre os organizadores e a audiência era fluida; não raro, pessoas completamente alheias ao grupo central traziam filmes para a exibição e ajudavam a montar os equipamentos. Às vezes, esses novatos vinham se agregar às reuniões de planejamento do cineclube, enquanto velhos participantes desapareciam, tragados por trabalhos finais e outros perigos da vida estudantil. De modo geral, era um grupo muito dinâmico e heterogêneo, e talvez sua única 
particularidade notável é que não incluísse ninguém ligado à produção, estudo ou crítica do audiovisual. À época, a UFES não possuía nenhum curso na área. Logo, em termos de cinema propriamente dito, os participantes poderiam ser todos considerados amadores ou leigos.

Nesse sentido, o aparecimento do Cine Falcatrua pode ser visto como uma realização daquilo que Michel de Certeau qualifica como práticas cotidianas do consumidor - os modelos de ação adotados por usuários que retêm "status de elemento dominado na sociedade" (1998, p. 11-12). Esses modelos, entendidos como "jeitos particulares de usar os produtos impostos pela ordem econômica dominante" (De Certeau, 1998, p. 13), são caracterizados como "diversas formas de pilhar furtivamente a propriedade alheia" (De Certeau, 1998, p. 12). O cineclube de fato resultava da apropriação de três recursos disponíveis: espaço, equipamento e mídia.

Em primeiro lugar, o espaço. Na segunda metade de 2003, ocorria uma ocupação estudantil num velho teatro da UFES, contra a decisão da reitoria de convertê-lo em um prédio de salas de aula. Se isso acontecesse, a comunidade acadêmica perderia não só um de seus centro culturais, como também parte de sua história viva: nos anos 70, o teatro havia abrigado o primeiro Cineclube Metrópolis, entidade que integrou a articulação do movimento cineclubista nacional na época da ditadura. Durante a ocupação, os estudantes tentavam manter uma programação funcionando no teatro, de modo a chamar atenção para a sua situação precária. Isso deu lugar a diversos tipos de atividades.

Pouco antes disso, diversos departamentos da universidade haviam recebido projetores DLP novos em folha. Esse equipamento, moderadamente custoso na época, estava sendo utilizado principalmente para a projeção de powerpoints durante as aulas. Alguns professores e alunos do curso de Jornalismo viram ai um desperdício do potencial desses aparelhos; eles acreditavam que os projetores poderiam ser mais bem utilizados na exibição de filmes, promovendo debates sobre cinema e dando corpo a uma disciplina virtualmente inexistente no curso. Só o que era preciso para dar-lhes esse uso era cumprir os devidos trâmites burocráticos.

A essas duas oportunidades locais, somava-se uma terceira, global: a popularização das redes ponto-a-ponto (p2p). Em 2003, devido ao aumento generalizado da velocidade de conexão com a Internet e ao desenvolvimento de codecs de vídeo mais eficientes (como reportado em Lasica, 2005), era possível compartilhar satisfatoriamente arquivos de filmes longa-metragem com qualidade de DVD. Por meio desses canais, os usuários obtinham acesso a inúmeros filmes que ainda não haviam sido - ou mesmo nunca seriam - 
oficialmente distribuídos no Brasil, desde os blockbusters da estação até títulos esquecidos de videoarte e documentários independentes de países estrangeiros.

A troca de arquivos era uma das atividades realizadas pelos estudantes durante a ocupação do teatro. Eles haviam trazido seus computadores pessoais para o acampamento no prédio da universidade, e usavam a conexão disponível - consideravelmente mais rápida do que as que tinham em casa - para baixar filmes, que eventualmente se reuniam para ver. Mas, como os computadores não tinham saída de vídeo composto ou gravadores de DVD, os estudantes acabavam utilizando simples monitores de $15^{\prime}$ para essas sessões de cinema improvisadas.

Essas razões favoreceram o aparecimento do cineclube como uma atividade que poderia simultaneamente 1) ocupar o teatro e 2) dar aos projetores da universidade um uso que os estudantes consideravam mais pertinente. Com ele, também viria a ganhar corpo uma dimensão face-aface da cultura de compartilhamento de arquivos: o cineclube permitia aos estudantes mostrar uns aos outros filmes que eram baixados individualmente, em um contexto cinematográfico mais próximo do tradicional. Ao implantar a lógica das redes p2p contra as regras de loteamento do campus universitário, os estudantes inicialmente adotavam um modelo de ação que não estava em plena "coerência com o espaço construído, escrito e pre-fabricado por onde se moviam" (De Certeau, 1998, p. 34). Entretanto, como pretendo demonstrar, essa atividade veio a produzir novas coerências no espaço, alçando os estudantes ao papel de projecionistas e curadores.

\section{Cinemas de improviso}

O cineclube foi batizado de Videoclube Digital Metrópolis, em homenagem ao seu predecessor, ainda que não houvesse nenhuma relação direta entre os dois. O plano dos estudantes era realizar exibições semanais gratuitas de obras audiovisuais dos mais diversos tipos. Na primeira sessão, o filme apresentado foi o clássico Matou a Família e foi ao Cinema (Júlio Bressane, 1969), para uma plateia bastante modesta - cerca de vinte pessoas. Na segunda, foi Kill Bill: Vol. 1 (Quentin Tarantino, 2003), que havia acabado de cair na Internet e não seria oficialmente lançado no Brasil em menos de dois meses. A popularidade desse título atraiu mais público; a maior parte das cadeiras do teatro estava ocupada. O boca-a-boca gerado prometia inserir definitivamente a atividade na vida cultural da UFES. 
Quando as pessoas apareceram na semana seguinte para uma terceira sessão, entretanto, deram com a porta na cara. O teatro havia sido fechado e já estava em vias de reforma. A ocupação estudantil estava terminada. O que teria acontecido com o cineclube? Aparentemente, a burocracia havia retardado seu aparecimento até que fosse tarde demais. Tendo acabado de firmar seu território, o Videoclube Digital o havia perdido, sendo obrigando a subsistir de uma forma completamente diferente. A partir de então, o cineclube teve que procurar um novo lugar a cada semana, adaptando suas projeções às situações mais diversas. Isso demandava certos improvisos técnicos e mudanças de última hora que minavam sua credibilidade junto à audiência. Logo, com a condição semi-nomádica, o cineclube obteve um apelido que expunha a aparente desorganização em que era obrigado a funcionar: Cine Falcatrua.

O novo nome também refletia o caráter ambíguo do material que o grupo utilizava e exibia. Ao invés do dispositivo cinematográfico normal, computadores "frankenstein", projetores de vídeo, velhas caixas mono e telas improvisadas. Nunca era possível incorporar plenamente esse equipamento à arquitetura dos espaços de exibição. Eles tinham que ser instalados antes de cada sessão, frequentemente às vistas da audiência. Mesmo depois que tudo estivesse no lugar, podia acontecer de o projetor ter ficado em uma posição vulnerável no meio do auditório, ou os cabos de som e energia estarem emaranhados por todo o chão. Alguém precisava ficar de olho no equipamento durante toda a projeção, para prevedir eventuais acidentes. Ainda assim, problemas sempre ocorriam. Um computador pessoal ainda era um reprodutor de filmes muito instável.

Improvisos parecidos se passavam na tela. Como mencionado anteriormente, a programação do cineclube era constituída principalmente por filmes encontrados na Internet, de fontes disputadas ou ilegais. Quem poderia assegurar a sua legitimidade? Ainda que a maior parte das cópias exibidas no Cine Falcatrua não fossem diferentes do corte final de uma obra traduzido para o formato digital, algumas eram bem diferentes das versões que costumam circular oficialmente, que tentam apagar da imagem as marcas de sua projeção. Isso era especialmente comum se o filme fosse recente e ainda não possuísse uma versão doméstica da qual um arquivo digital pudesse ser extraído de maneira "limpa".

Entre essas cópias bootleg, dois tipos frequentemente apresentados nas sessões do Cine Falcatrua eram os cams e os screeners. As primeiras são aquelas gravadas ilegalmente de dentro do cinema por alguém posicionado na plateia; as outras, feitas a partir de fitas ou DVDs promocionais distribuídos 
para a imprensa ou para as lojas/locadoras antes do lançamento comercial do filme (NS/VCDQ, 2010). Ambos os tipos costumam ser encontrados em redes de compartilhamento. Uma de suas particularidades é que elas expõem processos extraordinários de circulação dentro do próprio conteúdo do filme. Os cams costumam apresentar uma imagem orgânica, característica do filme reprocessado em vídeo digital sem muito cuidado, com cores, enquadramento e velocidade alterados. O som costuma ser abafado ou sobreposto por ruídos externos. De fato, se tratam de filmes do filme, feitos em condições precárias condições que se apresentam quando a imagem sai de foco ou é entrecortada pela silhueta de algum espectador que tenha participado da projeção original. Cópias screener, por sua vez, costumam ter perfeita qualidade técnica. O que pode acontecer é que o conteúdo do filme ainda não seja o definitivo: algumas ainda não passaram por todos estágios de pós-produção, como correção de cores, filtros ou mesmo efeitos especiais. Outras possuem indícios de sua condição extra-comercial, como marcas d'água, cartelas de advertência ou trechos de imagem monocromática. Auto-biográficas, elas contam uma história que não é só da obra, mas também a sua própria.

Em face desses fatores, poderíamos dizer que as sessões do Cine Falcatrua negavam sua própria condição midiática ao assumir a realidade tecnológica - uma realidade que não era simplesmente a da produção do filme, mas dos diversos processos individuais que formavam cada projeção. Toda sessão demandava esforços ativos para uma organização de estruturas que seria dada em uma situação cinematográfica normal. A audiência podia testemunhar - e frequentemente colaborar com - a constituição do dispositivo cinematográfico.

Nessas condições, era possível ver o dispositivo em sua forma mais primitiva, como uma organização abstrata de elementos: "cada unidade teorética e material tratada como um absoluto que tem sua própria perfeição intrínseca que precisa ser constituída como um sistema fechado de modo a funcionar" (Simondon, 1958, p. 20). Nesse estágio de constituição, a coerência do objeto técnico parece depender fundamentalmente de processos externos a ele. De um lado, para os envolvidos na organização do cineclube, isso implicava encontrar fontes de eletricidade, instalar o projetor e a tela, conectar os cabos apropriados, prevenir que a audiência interrompesse o facho de luz. De outro, para a plateia, implicava ignorar todas essas distrações de modo a poder aproveitar o filme. Na próxima sessão, pretendo mostrar como a especialização dessas atividades pode ter levado a uma crescente coerência técnica, resultando em um dispositivo mais bem adaptado a esse ambiente impróprio. 


\section{Da experiência cinematográfica ao engajamento tecnológico}

Uma particularidade do Cine Falcatrua era o modo como o cineclube buscava promover as plataformas on-line como canais próprios para a distribuição cinematográfica. $O$ grupo preparou textos e até uma vinheta animada argumentando em favor dessa causa. Durante as exibições, eram distribuídos panfletos que ensinavam ao público como baixar filmes da Internet e usar esse material para montar a programação de seus próprios cineclubes. Doravante, o cinéfilo pirata parece menos com o consumidor tático enaltecido por De Certeau do que com um regente de novas interações entre sistemas midiáticos. Essa é a figura utilizada por Simondon para demonstrar a importância do ser humano no desenvolvimento tecnológico: "é por meio dele que os membros da orquestra [as entidades técnicas] afetam a interpretação uns dos outros $(1958$, p. 13). Tais conexões entre sistemas viriam a produzir sinergias operacionais, levando a meios mais especializados e portanto mais concretos.

Nesse sentido, pode ser esclarecedor comparar a pirataria à prática de circuit bending, concebida pelo artista Reed Ghazala como um método para criar instrumentos musicais a partir de brinquedos eletrônicos baratos, baseado no "curto-circuito criativo encontrado por acaso" $(2005$, p. 8$)$. O circuit bending se caracteriza por ser um modo intuitivo e exploratório de criar novos fluxos de energia entre os componentes de um circuito por meio da reorganização de suas conexões (Ghazala, 2005, p. 3-4). De um maneira similar, o Cine Falcatrua parecia querer rearranjar a estrutura do circuito cinematográfico, fazendo pontes entre as instituições estabelecidas nesse contexto e o consumo midiático desautorizado.

Adotando essa mentalidade, os estudantes logo se tornaram muito eficientes na distribuição de filmes. Poderíamos dizer, empregando os termos de Vilém Flusser, que de meros funcionários do dispositivo eles se tornaram literalmente seus programadores, capazes de definir como o dispositivo opera (2000, p. 29-30). Mais de uma vez, o Cine Falcatrua exibiu filmes meses antes de seu lançamento no Brasil, para uma plateia de dezenas de pessoas. Alguns exemplos que podemos citar são o supracitado Kill Bill: Vol. 1 e o documentário Fahrenheit 9/11 (Michael Moore, 2004). Da mesma forma, o cineclube apresentava obras independentes e alternativas, que haviam sido censuradas ou esquecidas, ou que talvez simplesmente não fossem interessantes (lucrativas) o bastante para os distribuidores. 
Esse é mais ou menos o caso do dia que estou tentando recordar. Tínhamos encontrado uma cópia do longa Amor Estranho Amor (Walter Hugo Khouri, 1982), de péssima qualidade, provavelmente capturada de uma fita VHS. O filme é popularmente conhecido por apresentar Xuxa, a apresentadora infantil, no papel de uma prostituta que dorme com um garoto de doze anos. O filme foi realizado em 1979, quando a própria Xuxa estava no início de sua carreira, com não mais que 16 . Com base na alegação que não havia liberado sua imagem para distribuição da obra em vídeo, Xuxa conseguiu uma liminar que praticamente impossibilitava a sua circulação. Desse modo, Amor Estranho Amor adquiriu um status lendário: embora muitos já tivessem ouvido falar sobre ele, poucos haviam visto sequer uma cena do filme.

Como esperávamos uma sessão lotada, tomamos as devidas precauções. Reservamos um auditório com duzentos lugares e começamos a montar os equipamentos com muita antecedência. Não obstante, meia hora antes do início da sessão, todos os lugares estavam ocupados, e o público não parava de chegar. Para acomodar toda aquela gente, resolvemos transferir a projeção para o gramado do lado de fora. A possibilidade dessa mudança de última hora demonstra como a tecnologia era empregada pelo Cine Falcatrua de um modo muito mais flexível do que pelos sistemas cinematográficos convencionais. Deslocando o equipamento, o grupo foi capaz de organizar a projeção de um modo que teria impossível em um cinema convencional. Nesse sentido, é preciso levar em consideração que o que restringe o cinema não é seu viés comercial. Qualquer gerente de multiplex ficaria muito feliz em acomodar mais público do que o espaço permite, se ele assim pudesse. Mas isso não é viável porque o dispositivo cinematográfico normal é integrado a uma certa arquitetura, delimitada por certas regras (como de lotação máxima). A mera mudança tecnológica não é capaz de desfazer essa inércia operacional.

A situação na universidade, por sua vez, era outra. Inicialmente, o fato de a instituição não estar preparada para um cineclube parecia uma desvantagem, já que transformava cada sessão em uma tarefa arriscada e trabalhosa. Mesmo a exibição de um filme em um auditório demandava certo esforço calculado. Por outro lado, essa precariedade dava condições para novas organizações tecnológicas. Frouxamente conectado aos canais regulares de distribuição cinematográfica, às instalações institucionais, e mesmo aos prédios da universidade, o Cine Falcatrua tinha liberdade para explorar todas as possibilidades dos equipamentos digitais. Para o cineclube, montar uma projeção ao ar livre não era uma atividade mais extraordinária que montá-la dentro de um auditório. 
Nesse sentido, poderíamos sugerir que a atividade pirata do Cine Falcatrua aponta para um aperfeiçoamento discontínuo porém maior do dispositivo cinematográfico. A transformação que o cineclube causou nos modos de interação entre projetores domésticos, redes p2p e o ambiente universitário incrementou "de maneira essencial a sinergia de funcionamento" desses elementos em prol da exibição cinematográfica (Simondon, 1958, p. 34). Assim, o cineclube parecia ter encontrado uma solução possível para a projeção digital de filmes, seu circuit bending proporcionando a adoção antecipada das novas tecnologias. Por mais improvisada que pareça, essa solução se mostrou muito mais adequada para sua situação particular, possibilitando coerência operacional o bastante para sustentar exibições regulares por meses, numa época em que cinemas digitais eram uma realidade distante da maior parte das cidades brasileiras.

\section{A mediação jurídica da ontologia midiática}

Até aqui, o Cine Falcatrua parece ter sido bem-sucedido na imitação das operações cinematográficas convencionais. Integrando tecnologias digitais à projeção de filmes, a sua prática parece indicar um alargamento das especificidades do meio. Entretanto, não foi assim que o cineclube foi inicialmente incorporado ao circuito cinematográfico. Ao ser reconhecido como um componente do cinema, o grupo foi tornado ilegal. Esse desfecho nos permite entender quão rigidamente o arranjo dos dispositivos cinematográficos pode se impor por meio das estruturas aparentemente secundárias que os conectam.

Depois dos primeiros meses de atividade, o Cine Falcatrua já havia se inserido na vida cultural da cidade. As exibições semanais juntavam dezenas de pessoas, e não seria exagero dizer que ele havia se tornado um evento popular, aparecendo regularmente na mídia local. Em Julho de 2004, essa cobertura de imprensa atingiu níveis nacionais: o cineclube havia atraído a atenção da Folha de São Paulo.

O primeiro contato aconteceu on-line. Um repórter, procurando fontes para uma matéria sobre Vídeo CDs, esbarrou na comunidade do cineclube no Orkut e resolveu fazer um artigo a respeito dele. Ele entrevistou o grupo por telefone e mandou um fotógrafo para documentar uma das sessões. Acostumados a dar entrevistas, os participantes explicaram como o projeto funcionava, ressaltando o fato que ele possibilitava aos estudantes ter seu próprio cinema e experimentar com a exibição de filmes na universidade. 
Acostumado a trabalhar segundo os princípios do jornalismo, o repórter se dispôs a ouvir o "outro lado" da história, e foi perguntar a opinião da Associação de Defesa da Propriedade Intelectual (ADEPI) sobre a atividade do Cine Falcatrua.

Aqui, podemos abrir um parênteses para considerar como a fonte escolhida pelo repórter para comentar as exibições do cineclube revela uma certa predisposição quanto ao modo como essas exibições seriam acomodadas no circuito cinematográfico estabelecido. Nada o impediria, por exemplo, de ter colocado na matéria as visões de um diretor de cinema ou de outro cineclubista mais tradicional, defensor do filme em película. Ao evocar a posição de uma entidade jurídica, o repórter assume que a principal disputa em que o Cine Falcatrua estaria envolvido não seria entre diferentes paradigmas midiáticos, mas sim a guerra entre detentores do copyright e advogados da cultura livre que se espalhava pelo país devido à escalada da pirataria musical.

Invariavelmente, o artigo publicado no caderno llustrada de 29 de Julho de 2004 trazia declarações de um representante da ADEPI condenando as ações do Cine Falcatrua como criminais. Conforme essa notícia se espalhou pelo país, ela veio atrair a atenção de duas distribuidoras de filmes (Lumière e Europa Filmes) cujas obras haviam sido exibidas pelo cineclube. Menos de duas semanas depois, a universidade seria processada por essas empresas, além de receber uma queixa-crime movida pela ADEPI contra os participantes do projeto. O processo acusava a universidade de "concorrência desleal".

Em todo o seu absurdo, essa acusação poderia ser tomada como um atestado de autenticidade do Cine Falcatrua. De certa forma, ela representa um reconhecimento jurídico de que o cineclube estaria fazendo o trabalho de distribuição cinematográfica, e de um jeito ainda mais eficiente que as próprias empresas autorizadas para tanto. Aí está o porém: ao mesmo tempo em que legitimava a atividade do cineclube como uma prática de cinema, o processo o desautorizava dentro do circuito cinematográfico. Logo, ao invés de elevar o uso que o Cine Falcatrua fazia de tecnologias digitais a uma nova forma de exibir filmes, o processo o reduzia a meras "exibições ilegais de propriedade intelectual".

A partir desse ponto, o maior desafio do cineclube não era propor diferentes perspectivas sobre as especificidades do cinema - declarando, por exemplo, que a existência de um filme era secundária a sua exibição -, mas sim sustentar essas perspectivas em um tribunal. A instituição cinematográfica havia trazido a negociação das especificidades do meio de volta ao seu território 
tradicional, onde a lei poderia agir como o derradeiro árbitro da ontologia do cinema.

Diferentes setores da universidade reagiram ao processo de maneiras contraditórias. A reitoria pretendia colocar toda a culpa nos participantes do cineclube, como se eles tivessem não apenas cometido um crime, mas também traído a confiança da instituição. Professores e estudantes defendiam-no com base na ideia que a universidade deveria ser livre para investigar e experimentar com tecnologias alternativas de distribuição cinematográfica. Grupos civis que apoiaram o cineclube, como o capítulo local da Associação Brasileira de Documentaristas (ABD-ES), argumentavam pelo direito universal de acesso a cultura.

O problema com esses discursos é que eles reduzem as possibilidades mais radicais sugeridas pela prática do Cine Falcatrua: em primeiro lugar, que qualquer engajamento com a tecnologia midiática possui uma dimensão experimental inerente; em segundo, que a circulação de cultura tem menos a ver com a produção e consumo de bens imateriais do que com a criação de meios para compartilhar e acessar essas coisas.

Em Novembro de 2007, a disputa jurídica seria finalmente resolvida. Nenhum participante terminou autuado criminalmente, mas a universidade foi condenada a pagar cerca de $\mathrm{R} \$ 4.000,00$ de compensação para as distribuidoras. Ainda assim, é possível ver algum resultado positivo no processo, por mais colateral que ele possa ter sido. Depois de ter se espalhado nacionalmente, a controvérsia a respeito do Cine Falcatrua se tornou um ponto central na reorganização do Conselho Nacional de Cineclubes (CNC), que havia estado virtualmente inativo desde os anos 1980. A defesa do Cine Falcatrua foi uma das primeiras causas em torno das quais os novos membros do Conselho se reuniram; eles fizeram um abaixo assinado e publicaram uma carta aberta em apoio ao grupo no primeiro número de sua recém-criada revista. $O$ caso também foi um dos tópicos mais debatidos em sua primeira conferência, em 2004.

A consequente articulação política dos cineclubes levaria o Ministério da Cultura a criar em 2007 um edital para "Pontos de Difusão Digital", que tinha por objetivo distribuir equipamentos de projeção, junto com um pacote de filmes brasileiros em DVD, para entidades em todo país. Assim, enquanto a UFES estava sendo condenada por permitir a atividade do Cine Falcatrua, poderíamos dizer que a prática do cineclube digital finalmente ganhava um lugar definido no circuito cinematográfico, por meio da criação dessa estrutura secundária para a sua promoção e manutenção. 
Mas essa fixação não trouxe apenas suporte, como também uma série de restrições para a prática. De modo a qualificar como um cineclube, um grupo precisava ser uma pessoa jurídica que cumprisse certos parâmetros predefinidos no edital. Esse instrumento estipulava a supervisão do Ministério a todas as atividades realizadas, que precisavam ser comunicadas por relatórios periódicos. De acordo com o contrato de participação no programa, os cineclubes se comprometiam a organizar um certo número de exibições por mês, usando os filmes fornecidos, e corriam o risco de ter todo o equipamento apreendido caso exibissem obras piratas. Nesse sentido, a localização das práticas de cineclubismo digital parece tê-las cristalizado, limitando seu campo de operação.

De igual maneira, não seria errado dizer que o processo acabou por cristalizar o próprio Cine Falcatrua. O número de pessoas envolvidas na organização diminuiu consideravelmente depois das controvérsias jurídicas, de modo que os poucos que restaram precisaram assumir responsabilidades e compromissos cada vez maiores no seu funcionamento. Assim, o grupo ganhou contornos mais definidos, passando a operar menos como um cineclube do que como um coletivo de artes. Não coincidentemente, no ano após o processo, o grupo foi selecionado pelo projeto Rumos Artes Visuais do Instituto Itaú Cultural, que mapeia jovens artistas pelo país. Logo, em outro desenrolar aparentemente contraditório de eventos, a pirataria acabou sendo recebida pelo mundo das artes como uma tendência estética emergente.

Entre 2006 e 2008, o Cine Falcatrua atuou em parceria com uma série de instituições culturais brasileiras respeitadas, tendo participado também de exposições coletivas em alguns espaços de arte tradicionais (como o Paço Imperial, o Paço das Artes e o Museu da Vale). Nesse novo contexto, ainda que o projeto do grupo não tenha se alterado fundamentalmente, ele foi completamente re-enquadrado: da curadoria de cinema, passou a implicar a produção de obras. A pirataria, que era um método para a primeira atividade, passou a ser como que um conteúdo da segunda - a característica que tornava a prática do cineclube particularmente relevante enquanto arte. Dessa forma, ainda que sua atividade tenha se tornado mais simples de se realizar, também parece ter sido reduzida a uma encenação de si mesma, desarmada de suas implicações mais radicais. 


\section{Conclusão}

Em todas essas reorganizações de autorizações e recursos, podemos estar testemunhando estágios cruciais do devir do cinema enquanto entidade técnica, conforme o meio busca um novo grau de concretude a partir de sinergias de funcionamento com sistemas sociotécnicos mais amplos. Instrumentos aparentemente secundários ao cinema, desde fanzines e oficinas até programas de financiamento estatal, são os lugares onde essas sinergias são por fim negociadas e sustentadas. Esse tipo de aparelho parece operar em prol da normalização de práticas emergentes no circuito cinematográfico. Práticas que não podem ser implementadas dessa forma são separadas do meio, vindo a se acomodar em campos onde podem ser promovidas livremente - como o mundo da arte. De qualquer modo, os novos elementos se cristalizam como componentes internos ou externos ao meio.

Cada vez mais, parece crítico manter uma consciência do papel de tais territórios auxiliares na produção das especificidades do meio, particularmente em face das guerras de patente que têm sido travadas pelos mais diversos atores. Há empresas que operam simplesmente obtendo o maior número possível de patentes vagas e lucram processando outras entidades pelo seu uso. Envolvendo litígios de muitos milhões de dólares, esses casos estabelecem um patamar bastante elevado para o indivíduo inventor, que na maior parte das vezes não tem recursos sequer para contestar a sua legitimidade.

Nesse contexto, ao invés de favorecer o desenvolvimento tecnológico, os instrumentos legais são usados contra ele. Conforme esse gerenciamento de patentes é empregado para definir a padronização dos formatos de mídia digital, as noções do que é próprio e do que é propriedade se misturam de maneira perigosa. Em um tal cenário hiper-regulado, a pirataria pode ser não apenas uma forma de adoção antecipada de novas práticas midiáticas, como talvez uma das poucas formas de resistir à apropriação do devir técnico por interesses corporativos.

\section{Referências}

ASSIS, Diego. “Liminar impede sessões do Cinefalcatrua”. Folha de São Paulo, 12 ago. 2004. 
ASSIS, Diego. "Universidade federal em Vitória decreta 'falcatrua' no cinema." Folha de São Paulo, 29 jul. 2004.

DE CERTEAU, Michel. A Invenção do Cotidiano. 3a ed. Petrópolis: Vozes, 1998.

DE LUCA, Luiz Gonzaga Assis. Cinema Digital - Um Novo Cinema?. São Paulo: Imprensa Oficial, 2005.

FLUSSER, Vilém. A Filosofia da Caixa Preta. Rio de Janeiro: Relume Dumará, 2002.

GHAZALA, Reed. Circuit Bending - Build Your Own Alien Instruments. Indianapolis: Wiley Publishing, 2005.

LASICA, J. D. Darknet: Hollywood's war against the Digital Generation. New Jersey: John Wiley \& Sons 2005.

NS/VCDQ. 'FAQ - Video Sources,' VCDQ [on-line]. 2010. Disponível em: < http://goo.gl/ vhxDg >. Acesso em: 14 ago. 2011.

SIMONDON, Gilbert. On the Modes of Existence of Technical Objects, Paris: Aubier, 1958. Trad. Ninian Mellamphy, Canada: University of Western Ontario, 2008 [online]. Disponível em: <http://goo.gl/7zEmg>. Acesso em: 14 dez. 2012. 